\title{
Social Enterprise Emergence from Social Movement Activism: The Fairphone Case
}

\begin{abstract}
Effectuation theory invests agency_intention and purposeful enactment — for a new venture creation in the entrepreneurial actor(s). Based on the results of a 15-month in-depth longitudinal case study of Amsterdam-based social enterprise Fairphone, we argue that effectual entrepreneurial agency is co-constituted by distributed agency, the proactive conferral of material resources and legitimacy to an eventual entrepreneur by heterogeneous actors external to a new venture. In the context of social movement activism, we show how an effectual network pre-committed resources to an inchoate social enterprise to produce a material artefact because it symbolised moral values of network members. We develop a model of social enterprise emergence based on these findings. We theorise the role of material artefacts in effectuation theory and suggest that, in the case, the artefact served as a boundary object, present in multiple social words and triggering commitment from actors not governed by hierarchical arrangements.
\end{abstract}

Keywords: Social entrepreneurship; effectuation; distributed agency; material artefacts; social movement; longitudinal case study. 
The Democratic Republic of Congo (DRC), a vast mineral-rich country in Central Africa, has witnessed devastating civil conflict related to mineral exploitation. Mineral ores mined in the context of the conflict — called 'conflict minerals' (OECD, 2013) — are the raw materials used to manufacture the vital components of electronic devices such as smartphones. In September 2009, Peter van der Mark, a public relations (PR) expert, and Bas van Abel, ${ }^{[1]}$ an industrial designer, devised a campaign to raise awareness in the Netherlands about the connection between smartphones and the conflict in the DRC. They called their campaign Fairphone. They invited the Dutch public to develop collaboratively a 'fair' smartphone: a phone that would be 'conflict-mineral free'. They had neither the intention nor the expertise to make a commercial product. They hoped that any resulting prototype would be a non-functional concept device destined for exhibition at a local museum. They were wrong.

By January 2013, Fairphone the campaign had morphed into a social enterprise with Van Abel as founder/CEO and with a new objective: 'to produce a cool phone that put human values first.' In mid-2013, with no prototype, no customer base, no employee with industry experience and limited working capital, Van Abel and his staff of six launched a crowdfunding campaign via the company's website. They expected to pre-sell a maximum of 5,000 fair smartphones. They were wrong again. By November 2013, Fairphone had pre-sold 25,000 non-existent smartphones at $€ 325$ apiece. How do we theorise the unlikely emergence of Fairphone?

We present the findings of a 15-month longitudinal case study of Fairphone. Drawing on the social movement, commercial entrepreneurship, social entrepreneurship, technology entrepreneurship literatures and on effectuation theory, we develop a model that offers three key insights into social enterprise emergence. First, agency-intention and purposeful enactment-for social enterprise emergence does not inhere solely in the venture founders, as is assumed in effectuation theory (Sarasvathy, 2001; Sarasvathy, 2008, p. 15-16). The entrepreneurial intention and capabilities that are presupposed by a purposive enactment of the 
venture in effectuation theory may also originate from multiple actors-media, influential corporate actors, government officials - external to the entrepreneurial team. Distributed agency co-constitutes or enables effectual entrepreneurial agency in the creation of a new social venture in two ways: (1) by the proactive commitment of entrepreneurially-valuable material resources, legitimacy, capabilities and contingencies to the (eventual) effectual entrepreneurial agent, which are necessary for the new venture to thrive (Zimmerman and Zeitz, 2002); and (2) by eliciting a change in the intentions of a previously-reluctant effectual entrepreneur to pursue domain-specific entrepreneurial goals - a necessary condition for new venture emergence (Katz and Gartner, 1988).

Second, material artefacts, which were central to the development of effectuation theory (Sarasvathy and Dew, 2005; Sarasvathy, 2008, p. 246-254), but ignored in subsequent work on the theory, are vital to the convention of an effectual network. The symbolic dimensions of a material artefact — a smartphone - triggers resource pre-commitments from members of the effectual network. These members commit resources to the venture not based on assessments of utilitarian benefits, but because they interpret the artefact as symbolising their beliefs and values.

Third, the material artefact, a smartphone, served as a boundary object (Star and Griesemer, 1989) because it is comprehensible, possesses emotional power and enables contributions from members of different social domains-consumer electronics firms, government actors, consumers, hackers-who attributed various meanings to the artefact (Bijker, 1987). We propose that the concept be extended to include interactions that are not bounded within a single organisation as is the case in current organisational research on boundary objects (e.g., Nicolini et al., 2012; Yakura, 2002).

We begin our paper with a review of effectuation theory and distributed agency, the principal conceptual dimensions of the study. Next, we describe the method used in this 
paper - a longitudinal case study. We report our findings by presenting a summary of the case, the themes and the model of social enterprise emergence. Thereafter, we discuss the implications of our findings and, finally, we conclude with directions for future research.

\section{THEORETICAL CONTEXT}

In this section, we present the main concepts that emerged as we analysed Fairphone's history by pattern matching and referencing appropriate literatures. As we will discuss in the 'Methods' section of the paper, we employed an abductive inferential approach (Van Maanen et al., 2007) to adduce the best analytical explanation for the data, rather than deriving these deductively from prior theory before analysis of case. If we presented the paper how the study unfolded, we would have to report our methods and data before the reader learns what the main conceptual components and contributions of the study are likely to be. In order to furnish the reader with advance conceptual clarity (Suddaby, 2006), we abandon an abductive reporting approach. Instead, following traditional paper presentation approaches, we present the theoretical context first to preview the findings and the contributions.

\section{Effectuation and the Creation of Social Enterprises}

Like their commercial counterparts, social entrepreneurs act under conditions of uncertainty (McMullen and Shepherd, 2006) as they combine resources to form new products, services or organisations intended to stimulate social change or meet social needs (Mair and Martí, 2006). A valuable starting point for understanding entrepreneurial action under uncertainty is Sarasvathy's (2001) theory of effectual decision making or effectuation.

Sarasvathy (2001) argued that entrepreneurial action under an effectuation logic differs from action under causal or traditional theories (e.g., Gartner, 1985) in the following ways: (1) effectual entrepreneurs are more likely to start developing entrepreneurial opportunities not with a specific goal, such as making profit, but by deploying three sets of means - their identity, 
knowledge, and networks; (2) they are more likely to assess risk using the principle of affordable loss (advance commitments to much resources they are willing to lose in a new venture) rather than the principle of expected returns (advance calculations about expected financial returns from the venture); (3) they focus on building alliances with a network of stakeholders, such as potential suppliers and customers, instead of on analysing and outwitting the competition; (4) they exploit unexpected contingencies to mould the emerging enterprise, instead of minimising contingencies; and (5) they act in order to control an unpredictable future instead of predicting an uncertain future.

Effectuation theory has been applied to explain the formation of new technology firms (Sarasvathy and Kotha, 2001) and new industries (Sarasvathy and Dew, 2005). In the so-called dynamic model of effectuation (Sarasvathy and Dew, 2005), the entrepreneur imagines some generalised desired ends (e.g., a new venture) achievable using available means. The entrepreneur then interacts with people that she knows or meets. Due to this interaction, a selfselected 'effectual network' (Sarasvathy and Dew, 2005, p. 548) comprising potential customers, financiers and collaborators emerges. Members of the effectual network precommit resources to the entrepreneurial idea based on the principle of affordable loss. This results in an expanded flow of resources and/or change in the entrepreneur's goals. Assuming the effectual network is not dismantled, this recursive process continues until an expanding cycle of resources and increasing constraints on the entrepreneur's goals coalesce to enable the formation of a new firm or new industry.

Though social entrepreneurship scholars have invoked cognate constructs such as stakeholder support and collective action (Corner and Ho, 2010; Haugh, 2007; Montgomery et al., 2012) to explain social enterprise formation, our review of the social entrepreneurship literature suggests that effectuation in the context of social enterprise emergence has not received much attention. Broadly speaking, social entrepreneurship scholars have explained 
social enterprise formation by explicitly or implicitly employing traditional and bricolage theories of entrepreneurial action. In traditional theories of entrepreneurial action, the entrepreneur deliberately seeks resources to found a new venture predicated on exploiting some pre-identified opportunity (Gartner, 1985). Thus, social entrepreneurs are reported to consciously leverage the assets of target constituencies (Alvord et al., 2004), actively develop social capital (Squazzoni, 2009) and proactively manage risks (Lumpkin et al., 2013) to achieve social change. They also purposively progress through a trajectory consisting of temporallydistinct, pre-figured stages as they build new social ventures (Haugh, 2007; Mair et al., 2012; Robinson, 2006). Applying bricolage theory, scholars have reported that social entrepreneurs make do with available resources, creating 'something from nothing' (Baker and Nelson, 2005, p. 349), as they found social ventures in resource-poor environments (Di Domenico et al., 2010; Mair and Martí, 2009).

Like traditional and bricolage theories of entrepreneurial action, effectuation theory locates agency - the intention and purposive enactment-of a new venture in the entrepreneurial actor(s) who embark on the venture creation process with the intention to develop some business aspiration. In Sarasvathy's (2001) seminal paper, for instance, she illustrates effectuation theory using the example of an imaginary entrepreneur who intended to start a restaurant business, Curry in a Hurry. The entrepreneur then deliberately sought resources and information to realise that goal. However, the nature of the eventual business was an emergent, i.e. unpredictable, outcome arising from repeated interaction and conceptualisation between the entrepreneur and the effectual network. ${ }^{[2]}$ Furthermore, in effectuation theory, the entrepreneurial actor(s) is the basic unit of analysis and the motive force propelling the process of venture creation (Sarasvathy, 2008, p. 244-253). As Arend et al. (2015) have pointed out, effectuation theory overlooks the role played by other actors in the 
entrepreneur(s)' broader environment - such as competitors-in constraining or coconstituting entrepreneurial agency and, ultimately, new venture formation.

Scholars in fields as diverse as leadership (Gronn, 2002) and technology entrepreneurship (Garud and Karnøe, 2003; Hargrave and Van de Ven, 2006; Van de Ven, 1993) have emphasised that the agency for outcomes such as organisational performance and the adoption of technology respectively does not rest in a single actor, but is distributed across multiple actors pursuing their particular, limited interests with varying levels of involvement (Garud and Karnøe, 2003). To illustrate the concept of distributed agency in the context of new firm and industry formation, we turn to emerging scholarship at the nexus of social movement and organisation theory (e.g., Davis et al., 2005; Weber et al., 2008).

\section{Distributed Agency: An Illustration from Social Movement Literature}

Social movements, defined as loosely-organised coalitions that provoke social change by challenging prominent social and cultural practices through sustained campaigns (Weber et al., 2008), promote the creation of new (social) ventures and industries. Diverse actors within social movements, such as the media and professional associations pursue varying interests (Rao et al., 2000), and in the process, furnish entrepreneurs with resources, capabilities and legitimacy - ingredients vital for the formation of new ventures.

Legitimacy for New Industry or New Venture. Social movement organisations (SMOs) and their allies in institutionalised political arenas such as policymakers embed their values into regulation, creating legitimacy for entrepreneurial activity that is aligned with those values (Hiatt et al., 2009; Sine and Lee, 2009). Increased legitimacy may foster the founding of organisations that may otherwise not have been formed. In Sine et al.'s (2005) study of the U.S. independent power sector, the passage of the National Energy Act prompted in part by social movement activism in the mid-late 1970s, legitimated the sector. Legitimation then had 
a stronger positive impact on the founding of firms by entrepreneurs employing risky technologies than those using established technologies.

Resources. As SMOs contest prominent social and cultural practices, they may inadvertently expand the pool of resources that entrepreneurs exploit to found new enterprises. In Hiatt et al.'s (2009) study of the American temperance movement in the period 1870-1920, the movement successfully delegitimated the brewery industry. As a result, owners of disbanded breweries sold their capital equipment at highly discounted rates to opportunistic entrepreneurs in the budding soft drinks industry.

The transfer of resources to entrepreneurs need not be inadvertent; it may also be deliberate. Sine and Lee (2009) studied the rise of U.S. wind energy sector in the period 19781992. They reported that ideologically-motivated entrepreneurs and investors, who eventually founded wind farms, were brought together through networks of the Sierra Club, an activist organisation that had been campaigning for legislation in favour of wind energy at the time.

Consumer Demand. People change their consumption patterns in response to moral suasion by SMOs thereby creating demand for alternative products or services advocated by SMOs (Bartley, 2007; Hiatt et al., 2009; Sine and David, 2003). In a study of the market for certified wood products, Bartley (2007) found that corporate purchasers of wood such as IKEA switched to certified wood products in response to boycotts and market-making practices of a coalition of grant-making organisations and environment SMOs including the Ford Foundation and the Rainforest Action Network.

In summary, effectuation theory is a valuable lens for examining entrepreneurial action under conditions of uncertainty. However, effectuation theory assumes that agency for a new firm rests with a small, delineable group of actors, namely the entrepreneur(s). We address this gap with our study of the emergence of Fairphone. We integrate our empirical results with insights on distributed agency from fields such as the social movement literature, which 
recognise that multiple actors may contribute resources and legitimacy to enable the founding of new firms.

\section{METHODS}

We began this study in October 2013, when the first author became researcher-in-residence at Fairphone with the intention to study the evolution of the organisation's capabilities. ${ }^{[3]}$ As we studied the organisation's unlikely history, we developed a focused research question: 'how do we theorise the emergence of the social enterprise, Fairphone?'

\section{Step 1: Data Collection}

To answer the research question, the first author collected data using interviews, participant observation within Fairphone and documentary sources.

Interviews. We employed both deliberate and emergent sampling techniques to recruit informants. For instance, in order to avoid elite bias (Miles and Huberman, 1994, p. 263), the first author interviewed all members of Fairphone, including temporary staff and interns. To identify informants outside Fairphone, he used snowballing techniques (Patton, 2001, p. 237). He asked Fairphone staff to introduce him to people who were knowledgeable about the company and contacted potential informants - some of whom were critical of Fairphonementioned in third-party reports about Fairphone. In total, the first author conducted 47 interviews with 38 informants representing 13 organisations. We summarise the interview data in Table I.

INSERT Table I ABOUT HERE

Interview protocols were structured as follows: informants' biographical information; their relationship to Fairphone; what role they or their organisation played in Fairphone's history; the challenges that they had faced in that role; and an open-ended section in which 
informants providing any information they deemed important to Fairphone's story. Interviews lasted 55 minutes on average. All but one interview were recorded and transcribed.

We relied principally on retrospective accounts to reconstruct the story of Fairphone before October 2013. Recognising that retrospective accounts might be inaccurate (Miller et al., 1997), we followed methodological recommendations to improve the accuracy of the accounts. First, we interviewed informants with first-hand knowledge of Fairphone. Second, we asked informants to recall specific events rather than generalised information or opinions. To reduce hindsight bias, we asked informants to remember a time when they thought that Fairphone might fail. Third, we asked the same questions to multiple informants.

Participant Observation. The first author had sustained access to Fairphone's members. Over a 15-month period (October 2013-January 2015), he visited Fairphone's Amsterdam offices 1-3 times per week (total 130 field visits). During these field visits, which lasted 6-10 hours per day, he observed interactions among Fairphone staff in formal settings, such as team meetings, and in informal settings, such as weekly social events and Christmas dinners. He made detailed notes within 24 hours of a field visit.

Documentary Sources. We employed Fairphone's archival documents and publicly-available data to understand the context in which Fairphone arose and to triangulate interview reports. Fairphone's archival documents included grant applications, financial reports, business plans and the results of a survey of Fairphone customers while publicly-available data included Facebook entries, 1,870 Twitter feeds, campaign videos, five press releases, five radio shows, 158 press articles, and three television shows.

\section{Step 2: Timeline Construction and Informant Validation}

The objective of this step was to produce an accurate, complete and fair account of the emergence of Fairphone (Patton, 2001, p. 559-561; Yin, 2009, p. 182-184). The first author 
prepared a detailed narrative and timeline of Fairphone's history. He validated the narrative with Fairphone members on two occasions. The first occasion was a dedicated $1 \frac{1 / 2}{2}$ hour lunch in April 2014 meeting during which he presented the narrative and received feedback from Fairphone staff about the organisation's history. The second occasion was an informal meeting in June 2014 with three of Fairphone's founding employees. The staff independently crosschecked the timeline and clarified discrepancies with the first author. At the end of this step, we identified three distinct phases in the emergence of the enterprise, which we label 'social activism,' 'transition,' and 'social entrepreneurship.'

\section{Step 3: Identification of Emergent Themes}

Our goal was to build theory from a rich, in-depth case study (Eisenhardt, 1989). We employed an abductive inferential approach (Van Maanen et al., 2007), iterating between data and extant theory in order to theorise about the case. Theme analysis was used to explain patterns in the emergence of the enterprise. According to Dutton and Dukerich (1991, p. 524), a theme is defined as 'recurrent topics of discussion, action, or both on the part of the actors being studied...that captures the central ideas or relationships' regarding our research question. Theme analysis was performed in four stages. First, the lead author noted in contact summary sheets (Miles and Huberman, 1994, p. 51-54), the concepts that had characterised interviewees' accounts of Fairphone's history. Second, these concepts were used as a starting list of codes. Using NVivo 10 qualitative analysis software, we then coded interview transcripts and secondary documents for actors' decisions, activities performed by the actors, situations in which the actors took those decisions, and events — defined as time-limited occurrences beyond the control of focal actors (Langley and Truax, 1994). We retained informants' 'in vivo' quotes if the quotes succinctly captured decisions, events and states in Fairphone's story. Examples of first-order codes are 'legitimacy accretion,' 'tangible resources,' 'artefact attributes,' and 'material ends.' 
Third, we then recursively collapsed codes into higher-level theoretically-distinct categories (Eisenhardt, 1989), iterating between the codes and the data. For instance, informant statements about the Fairphone team's rationale for using a smartphone for an awareness campaign ('artefact attributes,' 'material ends') were grouped into the category 'artefact as storytelling device.' At the end of this step of the theme analysis, we had a total of 384 codes.

Fourth, we collapsed categories further into themes following Braun and Clarke's (2006, p. 82) guidelines that themes should be not only prevalent across different data sources, but that they should also possess 'keyness', capturing important patterns in the data. In the 'Findings' section of the paper, we discuss the themes that emerged from our analysis.

\section{Step 4: Pattern Matching with Extant Theory}

In the fourth step, we compared the themes and the rich narrative with similar concepts within the social movement, commercial, social and technology entrepreneurship literatures in order to build a structured analytical explanation of the case (Yin, 2009, p. 141). After a detailed review of those literatures, we agreed to explain patterns of decision making in the data using effectuation theory (Sarasvathy, 2001; Sarasvathy and Dew, 2005). We then re-coded the data using constructs from effectuation theory as a list of codes. What means did Fairphone members employ? What goals did they start with and how did those goals change? How did Fairphone's members interact with an effectual network? What pre-commitments were made by the network? How did Fairphone's members leverage contingencies?

\section{Step 5: Reliability Checks}

In order to improve the reliability of the coding, two authors independently re-coded the ten most 'information-rich' interviews. (The first author re-coded all 47 interviews.) Then, all three authors discussed the codes - the codes from step 3 and the effectuation codes from step 4until agreement on the coding and categories was strong. This form of reliability check has 
been used to establish coding reliability in qualitative research published in top-tier management journals (e.g., Plowman et al., 2007).

\section{FINDINGS}

In this section, we present a detailed account of the creation of Fairphone and the themes that emerged from our analysis of the data.

\section{Chronological Narrative: From Awareness Campaign to Social Enterprise}

Since the mid-1990s, the mineral-rich DRC [Democratic Republic of Congo] has been engulfed in a civil war. Civil society organisations, such as Global Witness (U.S.) and a coalition of European organisations including SOMO [Centre for Research on Multinational Corporations] (Netherlands) and The Church of Sweden, have contended since the mid-2000s that global demand for mobile phones fuels the conflict because Congolese militia compete violently to control the mines that supply valuable mineral ores to the mobile phone industry (Pöyhönen and Simola, 2007). These NGOs [non-government organisations] and their allies in U.S. and European Union (EU) legislatures have lobbied for legislation against the use of conflict minerals in electronic products.

In September 2009, in this context of social movement activity, Mesa, an Amsterdambased NGO, approached Van der Mark for ideas about an awareness campaign. Founded in the mid-1990s as a merger of three NGOs that had campaigned against Apartheid in South Africa, Mesa had by 2009 shifted to campaigning for equitable distribution of mineral wealth in subSaharan Africa. In late September 2009, Mesa commissioned Van der Mark to develop an awareness campaign about the connection between smartphones and the conflict in the DRC.

Once Van der Mark and Van Abel had identified the idea for a collaborative hands-on fair smartphone campaign, they were joined by two programme managers from Mesa to form 
the Fairphone campaign team. In March 2010, the team secured a public grant to run their campaign. In the grant application they described their plan as follows:

Important minerals used in mobile phones are being mined in degrading circumstances in Congo. We want to make consumers aware of the terrible situation in the Congolese mines. [By making a smartphone] Together with consumers we want to convince smartphone manufacturers of the importance and possibility of making a fair alternative.

None of the four Fairphone team members knew how to produce a smartphone. The campaign was intended merely to raise public awareness as Fairphone's founder/CEO explained, 'I didn't even know about conflict minerals when I started this project...I was interested in making the ['conflict mineral-free'] phone from a purely design perspective... The whole aspect of bringing the phone to market did not interest me.'

With grant money in hand, the Fairphone team launched Twitter, Facebook and web pages in the summer of 2010 and invited the public to contribute ideas for a fair smartphone. While the campaign was underway in mid-2010, two events kept the DRC in the news: (1) the publication in the Netherlands of a bestselling book about the DRC's tragic history; and (2) the passage of the Dodd-Frank Act in the U.S.

Media and Industry Get Involved. In October 2010, only seven months after the campaign began, Fairphone was hailed as 'the world's first collective non-profit developer of mobile phones' by widely-circulated Dutch newspaper, De Volkskrant. In March 2011, the Fairphone team travelled to the DRC to source 'slavery-free' minerals and publicised the trip on the campaign website.

Shortly after returning from the DRC in March 2011, Van Abel was invited by the board of directors of Alpha-Mobile, a mobile network operator (MNO), to present Fairphone. Reflecting on the experience, Van Abel confessed, 'It was really weird...I was doing a presentation to the board of directors. I didn't even know what to ask these guys...People got 
excited and pulled me into the whole system [Alpha-Mobile].' Within the month, AlphaMobile agreed to buy 1,000 non-existent fair smartphones.

In the same month, the campaign team presented the Fairphone campaign project to an executive of Macrobank, a large bank, after which the executive publicly endorsed Fairphone. Van der Mark remembered that, 'They [Macrobank] gave us a little bit of money and they pushed us on their website.' In November 2011, the Fairphone campaign was voted as winners of a prestigious $€ 10,000$ prize for sustainable innovation in fair trade. Thus, remarkably by the end of 2011, the Fairphone team with no smartphone prototype, no intention to start a business and no expertise in the smartphone industry, had gained significant support for their project. But then, the Fairphone campaign team reached a crisis point.

Conflict, Uncertainty, Funding Problems. Conflict within the campaign team led to the withdrawal of Mesa. The Mesa members did not understand Fairphone's campaigning practice. A Mesa programme manager explained, 'we [Mesa] had one problem—that was the financing. The other problem was understanding Fairphone. What the hell is Fairphone?...It was a new way of communication. And we were old-school.' Mesa members also thought that being associated with Fairphone threatened their organisation's reputation:

How fair is Fairphone? Is it $1 \%$ fair? Is it $99 \%$ fair?...We [Mesa] took a lot of responsibility in the sense that if journalists would find out, like, Fairphone was not as fair as they claim to be, then because with our [Mesa's] name we were connected to Fairphone — as an organisation it will get back to us. (Mesa consultant \#2)

In addition to conflict over campaign practices, Fairphone had also run out of ideas and funds. Van der Mark recalled, 'Nobody really knew what to do with Fairphone...We were sitting around with some people making plans, but didn't know what to do. The first thing we thought about is, “why don't we make a battery?"... Nobody dared to say that we were going to build a phone.' By early 2012, with their funds exhausted and no support from Mesa, Van 
der Mark and Van Abel could not afford to work on Fairphone. Thus, they returned to their paying day jobs.

In March 2012, Miquel Ballester, a university student, applied to Waag (Van Abel's erstwhile employer) for an internship position. Van Abel immediately recruited Ballester to work on the Fairphone project for latter's master's thesis. Two months later, a project manager at Waag serendipitously discovered an opportunity to develop Fairphone: a London-based entrepreneurship incubator had put out a call for sustainable business ideas.

I remember, I think it was a Thursday, and I saw it coming in my inbox...it was not that I was actively looking for an acceleration [incubation] program...but reading the text, I said, 'this is what Fairphone needs right now'...And I submitted the Fairphone plan [to incubator] without consulting anyone. (Fairphone ex-project manager)

Fairphone was selected to attend the three-month incubation programme in July 2012. While in London, the Fairphone team, principally represented by the intern Ballester, met with telecommunication industry insiders, technology entrepreneurs and venture capitalists.

In September 2012, Van Abel and Ballester secured an investment of $€ 400,000$ from a business angel to incorporate a company. The angel explained his rationale for investing: 'Investment for me is not like figures. For me it's the story, it's the people...I wasn't calculating anything [when I invested]. It's a luxury position...And it's not a decision made on any plans. Nothing at all.' In January 2013, Fairphone the social enterprise ${ }^{[4]}$ was incorporated with Van Abel as founder/CEO, and Van der Mark and Ballester as co-founders.

Crowdfunding Drive, Media Attention. In February 2013, Van Abel was invited to the DRC by Prince Jaime de Bourbon de Parme, a member of the Dutch royal family and The Netherlands' Special Envoy for Natural Resources. The prince was leading a multi-stakeholder project to source conflict-free tin from the DRC. 'Would Fairphone be interested in participating in the 
pilot?' he asked. Van Abel had played no role setting up the pilot, but he agreed to buy conflictfree tin from the prince's project.

Despite the campaign promise, Fairphone could not afford to design a smartphone. Ballester recalled, 'We didn't design a phone [during the campaign]. We made...if you like, an artist's impression of what a phone could look like. To design a phone from scratch, you need millions of dollars.' With only $€ 400,000$ working capital, designing a smartphone was out of the question. In early April 2013, Van Abel agreed to license a smartphone design from a factory in China and to incorporate therein conflict-free components from Prince Jaime's pilot programme.

After deliberation, Van Abel and the Fairphone staff, now comprising six people (none of whom had phone industry experience), decided to finance production of the phone by appealing to the public in a 'crowdfunding' campaign. Their goal was to raise enough funds to cover the production of 5,000 smartphones at a unit price of $€ 325$. They were not hopeful that they would reach the sales target. Van der Mark said of the period, 'At first I thought, "Nobody is going to pay $€ 325$ for something you don't have, that doesn't exist."' Only three weeks after announcing the crowdfunding drive, all 5,000 smartphones were sold out.

The crowdfunding drive generated substantial international media coverage for Fairphone. Reflecting on the period, one Fairphone employee said, 'I have never been on a train that's run so fast...I was amazed that Al-Jazeera, the Wall Street Journal, CNBC, The Guardian and the BBC, everyone needed to report about us...the level of attention was quite amazing.' Customers called the company asking to pre-order more smartphones. Van Abel and his staff put an additional 20,000 phones on pre-sale. To their surprise, all smartphones were sold out by November 2013. Incredibly, in less than a year, Fairphone, the start-up with no industry track record, had pre-sold 25,000 non-existent smartphones. 
Producing the Fair Smartphone. Though Fairphone had the financial resources, the start-up did not have the technical expertise to produce a smartphone. In July 2013, Van Abel hired a chief technology officer (CTO)—Fairphone's first employee with smartphone industry experience. With help from contacts at Beta-Mobile, Van Abel and the CTO commissioned an audit of the Chinese factory. The results were disappointing: the factory did not have the capabilities to produce smartphones meeting the exacting quality standards of the European market. Following the audit, Van Abel hired specialists to ensure quality at the factory.

Nevertheless, quality problems soon emerged as the first prototypes were being made. (The first author joined Fairphone soon after the audit in October 2013.) The defect rate of the prototypes was about 105 per 100 produced smartphones, i.e. on average every prototype had 1.05 defects. The first author witnessed Fairphone staff frustration at the high defect rate and the seemingly intractable quality problems. One exasperated employee explained:

[T] he quality standards of [prototype] phones were completely different from what you would expect on a phone. There were no two phones that they [factory] built that the [power] button here [points to smartphone]...had the same feeling because of manufacturing differences...If you do not have this [smartphone] that works then you are done. Forget it. Done.

Throughout the prototype development process, however, Fairphone received help. Friendly contacts at MNOs Alpha-Mobile and Beta-Mobile tested prototypes and provided invaluable feedback to Fairphone free of charge. A director at Alpha-Mobile, who had instructed engineers at his company to test the prototypes, explained his support:

It's also a personal relationship you are [I am] having [with Fairphone]. Much more personal involved than we [Alpha-Mobile] do have with all the other smartphone vendors. We are doing hundreds of thousands of euros with other vendors, but this [relationship with Fairphone] is really only on personal belief, personal commitment. 
In October-November 2013, Fairphone staff in Amsterdam and in the factory worked with factory managers and MNO contacts to reduce prototypes defect. Van Abel explained the situation at the end of one test in November 2013 to the first author: 'I [will] only believe it when the phones are here. That's when I will feel relieved - and that the phones work, of course. We [Fairphone] are managing a lot of the processes [in the factories]. We have three people in five factories looking at the production aspects and working their butts off.'

In the first week of December 2013, Fairphone received more help. Engineers at GammaMobile, a German MNO, voluntarily resolved a software problem they had discovered while testing a prototype smartphone.

Basically, there was a bug [software failure] that made phone calls not work properly with Gamma-Mobile in Germany, which is $40 \%$ of our customers...They've fixed it now... If we hadn't connected with the right people at Gamma-Mobile, we wouldn't have known. (Fairphone co-founder, Miquel Ballester)

In early December 2013, the defect rates dropped to about 17 per 100 prototypes. Judging this to be an acceptable defect rate, Van Abel approved production of the first 2,000 fair smartphones. ${ }^{[5]}$ These were assembled and delivered to European customers on Christmas Eve 2013. In subsequent weeks, the factory shipped several thousand assembled phones per week to customers who had been waiting for three to six months. By February 2014, all 25,000 smartphones had been shipped to customers in 32 European countries. As we write this paper (October 2015), the company has pre-sold an additional 50,000 smartphones (total 75,000 phones; revenue $€ 27.4$ million) and grown to 45 employees. Simply put, Fairphone the social enterprise has emerged. Its founders demonstrated entrepreneurial intentionality, secured resources such as capital, established organisational boundaries and engaged in exchange across those boundaries (Katz and Gartner, 1988). 
Our analysis revealed four themes that characterise the emergence of Fairphone: 'perturbed contextual condition,' 'issue framing,' 'distributed agency,' and 'effectual decision making.' In the remainder of this section, we first present the three emergent themes, and then the evidence for effectual decision making.

\section{Theme 1: Perturbed Contextual Condition}

The data shows that industry actors, who were aware of failures along the electronics industry supply chain, responded to perturbations within the industry and, in the process, advocated various solutions to the problem of conflict minerals.

Awareness of Failure. Industry insiders were aware of problems across the consumer electronics industry supply chain. These problems included the opacity of the chain of custody as minerals travelled from the DRC's mines through traders to ore smelters, and poor working conditions in East Asian factories where smartphones are assembled. A manager from BetaMobile put the point concisely: '[W]e [industry] all know there's something wrong with our supply chain and our business modelling. We all know that. We also know that it's hard to change that.'

Disruption Event. Despite this awareness, the solution space available to address supply chain problems was not expanded until the consumer electronics industry experienced a disruption event (Meyer, 1982; Sine and David, 2003): the promulgation of the Dodd-Frank Wall Street Reform and Consumer Protection Act by the U.S. Congress in July 2010. The bill, which had been passed in response to the 2008 financial crisis, contained a section unrelated to the crisis, which required U.S. companies to demonstrate due diligence in sourcing minerals from the DRC.

One informant made plain his assessment of how the legislation affected the industry.

You had a huge bill [Dodd-Frank Act], you know, 10,000 pages,...[it] was passed through very quickly and attached to it was this [conflict mineral legislation] and it landed 
on the SEC [Securities and Exchange Commission]...they [SEC]...were, of course, completely unaware of how to handle this... So there you have this piece of badlycontradictory, badly-worded, badly thought-out wish-list [conflict mineral legislation] without any mechanism or idea in terms of how to actually effectively...put it into law...So it was a real mess [for industry compliance]. (Director, Delta-Electronics)

Solution Proliferation. The Dodd-Frank Act triggered three types of responses by actors: (1) Avoiding - Smelting companies and mining companies avoided sourcing from the DRC altogether to eliminate the risk of breaking U.S. law; (2) Legislating-European legislators and their civil society allies called for a European equivalent to the Dodd-Frank Act while some industry groups challenged the legislation in U.S. courts; and (3) Engaging-Some civil society groups, the Dutch government, and members of consumer electronics industry associations under the auspices of the OECD developed initiatives to source certified conflictfree minerals from the DRC.

\section{Theme 2: Issue Framing}

Issue framing refers to discursive and symbolic practices within Fairphone's campaign repertoire consisting of a number of distinct elements: 'articulated ideals of practice,' 'employment of artefact as story-telling device,' 'perceptions of actor distinctiveness,' and 'establishing category congruence.' Collectively, these elements trigger material support for the enterprise.

Articulated Ideals of Practice. The Fairphone campaign team repeatedly made normative claims justifying the campaign by articulating two ideals of practice: transparency and fairness. Mesa justified participation in the Fairphone campaign to external audiences by portraying the campaign as part of its fight against injustice in Africa. It did so by drawing on the organisation's previous campaigns against Apartheid. Waag, represented by Van Abel, 
justified participating in Fairphone by stressing the organisation's hands-on approach to product design. Waag's slogan, often repeated in documents: 'if you can't open it [a product] you don't own it.'

Artefact as Story-telling Device. Fairphone's founders used a smartphone as the centrepiece of their campaign. The attributes of a smartphone - tangibility, ubiquity, emotionality —informed that choice as one Mesa programme manager explained, 'It's [a smartphone's] just something which everybody uses and which is really important in people's lives. And that's why we went for the phone.'

Yet, the artefact was employed in differently by various team members. The smartphone was predominantly used for issue prognosis (Benford and Snow, 2000) — as a call to arms to the public to act and change the situation in the DRC. For Mesa, however, the artefact was a means of instrumental exchange.

[NGOs need] stories that are tangible. Mesa was working on something called 'democratisation of society' [before Fairphone]. That is not tangible I can tell you. You cannot turn that into a product and ten pictures each year to fund-raise on. But a phone that you and I use? I mean... It was just too good to be true if you could link yourself to something like that. (Mesa consultant \#1)

Establishing Category Congruence. While still a social movement campaign, Fairphone team legitimated the campaign by demonstrating that its objective was symbolically congruent (Lounsbury and Glynn, 2001) with an extant product category: Fair Trade. For instance, they chose the name 'Fairphone', similar to Fair Trade and portrayed their objective as a variation of a familiar product category, Fair Trade consumption. However, they did not attempt to establish category congruence in order to further entrepreneurial goals. Instead, they compared their campaign to Fair Trade in order to increase comprehensibility and 'taken-for-grantedness' (Suchman, 1995, p. 582) of the campaign repertoire with audiences. 
Perceptions of Actor Distinctiveness. We surmise from the data that informants perceived Fairphone to be distinct from both NGOs and smartphone manufacturers. Fairphone's 'positive' story, contrary to NGO's adversarial stance, engendered support from insiders:

They [Fairphone] said, 'Hey, couldn't we get conflict-free tantalum [metal used in smartphones]? We want to make a mobile phone.' And I think, this story is fantastic in itself in that the way they turned the story around [from how NGOs tell it] as it were, in that 'all mobile phone makers were evil,' but actually there was a way in which you could make a fair phone. I think, personally, that was brilliant. (Director, Delta-Electronics)

Distinctiveness, however, did not always yield support for Fairphone. Where an organisation's norms of practice and external legitimating criteria-for instance Mesa's — did not match Fairphone's, the organisation withdrew support for Fairphone.

\section{Theme 3: Distributed Agency}

Distributed agency refers to the proactive conferral of entrepreneurially-valuable material resources and legitimacy to Fairphone's founders by multiple, heterogeneous actors even before the founders had any intention to start an enterprise. We identified five types of distributed agents - corporate actors, the media, the public, government officials, and consumers - who provided direct and contingent endowments to Fairphone's founders. These endowments were beyond the immediate control or intention of Fairphone's founders.

Direct Endowments (Legitimacy, Material Resources). These endowments were made despite the fact that Fairphone's founders had no intention of making a commercial phone. Elite corporations provided funds and human capital to Fairphone, furnishing the founders with these vital building blocks for new venture (Zimmerman and Zeitz, 2002; Zott and Huy, 2007) for free. For instance, one informant lobbied to support Fairphone financially even though the campaign had no product — in violation of his company's purchasing policies. 
I said to him [Van Abel], 'no company in the world will give an order because we don't know the price, we don't know the product...Then I went to the legal department. They said, 'no, we are not going to make an order.'...And then I made a click with in those days a member of the board...He said, 'well, why not? What can be wrong?' Because I told him the storyline...He said, 'if it goes wrong, you are responsible.' (Director, AlphaMobile)

Furthermore, the media and public granted the campaign moral legitimacy, which Suchman (1995, p. 579) defined as audiences' 'positive normative evaluation of an organisation and its activities as "the right thing to do." Media endorsement of the campaign assumed that a fair smartphone would materialise in the future despite the campaign's lack of a performance record and no intention to make a product.

Every mobile phone drips with blood from Congo...Fairphone will make a fair smartphone with help from future users. You [reader] can help with the campaign, contribute to the design or travel to Congo to decide who Fairphone should purchase fair minerals from...Make sure that the fair phone comes. (Article Vrij Nederland, 30 April 2011)

The accretion of resources and legitimacy for the Fairphone campaign provided impetus to the founders to progress the idea beyond an awareness-raising campaign.

[W] hen we joined the prize [voted by public]...and we won... We got a lot of media attention. Every newspaper in Holland wanted to write about Fairphone...But I think the most important thing that happened there was that we all got the feeling: 'this [Fairphone] has to go on...We have to do something with this great idea.' (Fairphone co-founder, Peter van der Mark) 
Contingent Endowments. These are endowments of material and immaterial resources that occurred after the founders had decided to start an enterprise, but which involve action by the founders to exploit the opportunities inherent in the endowments. (See section on 'effectual decision making.') For instance, in 2013, professionals, such as hackers, marketing experts and experts on Chinese labour law, volunteered their services to Fairphone. These volunteers provided a pool from which Fairphone's founders hired new employees, thereby eliminating search costs for the start-up. The hiring of Fairphone's production manager in the Chinese factory, Margaret, illustrates this theme:

Margaret sent us an e-mail from Columbia University [in July 2013]. She said, 'I have seen Fairphone. I love the idea. I would like to work for you'...For some reason, there was something about Margaret's application that sparked something...Bas [van Abel] said, 'you know what, I am just going to invite her to China. We will work there for a week and if it works out, we will hire her.' (Fairphone co-founder, Miquel Ballester)

Fairphone staff exploited unexpected customer attention during the over-subscribed crowdfunding campaign. An ex-intern at Fairphone, surprised at customer support during the 2013 crowdfunding drive, said, 'we had people [customers] saying, "I don't care if it's a brick with numbers drawn on it. I will still buy it because of the mission." And that was so amazing for me coming from a marketing background. Essentially, we were selling air for €325.'

Though we do not have direct access to the motives or interests of the distributed agents, the data strongly suggests that actors' normative evaluation Fairphone's stated goal was crucial to the commitment of material resources. In a March 2014 survey of 730 customers who had pre-paid $€ 325$, respondents scored Fairphone very highly $(4.2 / 5.0)$ on the extent to which the brand fit their personal beliefs and values and reported that they had not done much rational search and deliberation before pre-ordering Fairphone (2.9/5.0). In Table II, we summarise the evidence for the emergent themes. 


\section{Effectual Decision Making}

The pattern of decision making in Fairphone's history shows the founders acting within available means, interacting with an effectual network, leveraging contingencies and changing goals to produce an emergent outcome that they did not originally intend. We present the evidence for effectual decision making in the study.

Acting within Means. Even when they had no intention to form an enterprise, Fairphone's founders exploited available means—identity, knowledge, networks (Sarasvathy, 2001)—to further the campaign goals. For instance, the campaign idea of co-creating a material artefact with the public drew on the principles of open design, which were familiar to Van Abel in his job as industrial designer at Waag. Mesa members of the Fairphone campaign team leveraged networks with journalists and grant agencies in The Netherlands to secure coverage for Fairphone and resources respectively.

Interaction with Stakeholders. In effectuation, a self-selected group of stakeholders contribute to the inchoate venture, shaping it in unexpected ways by interaction with the focal entrepreneurial actor (Sarasvathy and Dew, 2005). As Fairphone team members acted on their means they interacted with self-selected stakeholders who were interested in the problem of conflict minerals and labour conditions in smartphone factories. Fairphone's founders interacted with this network in the following ways: (1) in face-to-face meetings and workshops with journalists, government officials, MNO executives and civil society members; and (2) indirectly via print, electronic, social media and the campaign website.

One important member of the effectual network, the business angel, is associated with Van Abel's former employer, Waag. He had heard about Fairphone through contacts at Waag, who eventually introduced him to Van Abel in 2012. The angel explained: 'Of course I had a 
lot of information of what was going on here [Waag]. And a lot of things I discussed and I hear because I know them [Waag] very well. So I knew [of Fairphone].'

Changing Means, Changing Goals. Despite their original intention, Fairphone's founders had by September 2012 decided to found a company. This change of goals occurred by interacting with and accumulating resources from stakeholders such as the angel investor.

They [Fairphone campaign] were trying to sell a report about the terrible situation in Congo...They said, 'It is very difficult. They [the smartphone industry] accept us, but nobody listens.' [I said,] 'Of course, if you really want to change something you must be dangerous for them [the industry]... You must be part of the game [the industry]. Not just telling other people what they should do, but showing people that it can be different. (Angel investor)

Also, Fairphone founders, by interacting with industry insiders, gained knowledge (new means) about how smartphones were actually produced.

For me, being in London in September 2012, I guess, [it was] for me the first time that someone told me, 'we are going to make a phone'...For me, making a mobile phone is like going to Mars, you know, but these guys [Van Abel, Ballester] found out pretty quickly [in London] that...you don't have to make it [sic] your own. (Fairphone cofounder, Peter van der Mark)

Leveraging Contingencies. Contingencies, which are conceived as unexpected events that Fairphone's founders did not anticipate (Sarasvathy, 2001), occur as a result of the agency of actors external to the founding team. From the perspective of Fairphone's founders, these actions (resulting in contingent endowments as shown in Table II) were contingencies beyond their immediate control. Yet, the founders acted opportunistically, exploiting these events to further their immediate ends. For instance, in July 2012, Van Abel and Van der Mark could not 
attend the incubator programme in London for three months full-time. They encouraged Ballester, the intern with no ties in the Netherlands, to represent Fairphone.

He [Ballester] was a graduation intern before, and he was almost shocked that we gave him the opportunity to go to London. But for me it was very logical. [I said,] 'You [Ballester] are the only one. You're available.'... and Bas [van Abel] had a family so he could not go full-time to London. (Fairphone, ex-project manager)

Similarly, Fairphone's founders enlisted the start-up to participate in the conflict mineral initiative and exploited oversubscription of the crowdfunding campaign to produce 25,000 phones, instead of the originally-planned 5,000.

Affordable Loss Pre-commitments. This refers to advance commitments of resources (money, time, expertise) that an actor is willing to lose in supporting a new venture (Sarasvathy, 2001; Sarasvathy, 2008, p. 81-84). In our study, members of Fairphone's effectual network precommitted material resources and conferred legitimacy on the emerging social venture after the founders decided to make a commercial product. We identify three types of actors who made affordable loss pre-commitments to Fairphone: (1) investors, such as the venture capitalist firm and the angel investor; (2) corporate actors, such as MNOs Alpha-Mobile, BetaMobile, and Gamma-Mobile, who provided industry-specific expertise to Fairphone; and (3) cultural influencers, such as noted British activist George Monbiot (with over 140,000 Twitter followers), who tweeted in support of Fairphone in October 2014: 'My @Fairphone has arrived. My first smartphone. And, I hope, if it's as easy to repair as claimed, my last.'

To sum then, Fairphone's founders acted effectually. They acted within their means, exploited contingencies provided by a distributed network of actors, and, in the process, changed their goals while attracting and maintaining an effectual network of supporters. In Table III, we summarise the evidence for effectuation in the emergence of the social enterprise. 


\section{INSERT Table III ABOUT HERE}

\section{DISCUSSION AND IMPLICATIONS}

We motivated this study by attempting to theorise the unlikely emergence an enterprise, whose founders originally had no entrepreneurial intention and no capability to produce a complex product. We find that the firm's founders employed discursive and symbolic practices centred on a material artefact to frame their solution to a social problem. This triggered the accretion of resources and legitimacy, despite the founder's reluctance to start an enterprise. By acting using available means, leveraging contingencies and interacting with an effectual network, the founders changed goals and decided to found an enterprise. Thereafter, the effectual network provided support and legitimacy, leading to the outcome-a thriving social enterprise. We develop a model of social enterprise emergence, which summarises our findings. Refer to Figure 1.

\section{INSERT Figure 1 ABOUT HERE}

\section{Distributed Agency: The Accretion of Legitimacy and Resources}

The assumption that new ventures lack legitimacy is a 'core premise' among scholars of organisational legitimacy (Überbacher, 2014, p. 668). Yet, scholars have reported that new ventures need to be legitimate in order to acquire the valuable resources, which they typically lack. Thus, these scholars emphasise that entrepreneurs may act purposively to acquire legitimacy from their environment in order to overcome resource constraints (Aldrich and Fiol, 1994; Lounsbury and Glynn, 2001; Zimmerman and Zeitz, 2002). Our study of Fairphone suggests that an (eventual) entrepreneurial actor may also inadvertently acquire legitimacy and entrepreneurially-valuable resources despite having no entrepreneurial intention and no competence to transform inputs into economic outputs that its stakeholders want. 
Resource Availability within Perturbed Context. Unprecedented perturbations such as regulatory changes to an organisational field may disrupt the expectations of field members (Sine and David, 2003). These disruptions provoke multiple responses from organisational actors intended to obviate negative outcomes to their organisations (Haveman and Rao, 1997; Meyer, 1982) leading to a 'solution bazaar' (Sine and David, 2003, p. 188) —a situation wherein organisational decision makers search for appropriate solutions and other actors proffer solutions to the decision makers' needs.

Search processes and the solutions devised in the wake of such perturbations reflect different underlying ideologies, norms and values among heterogeneous actors (Garud and Karnøe, 2003; Meyer, 1982). Our research shows, for instance, that after the passage of the Dodd-Frank Act, European civil society organisations proffered solutions that: (1) located the cause of the conflict minerals problem in the electronics industry's sourcing practices; and (2) presumed that legal coercion was the most effective way of changing those practices. Consumer electronics firms, on the other hand, proffered market-based solutions privileging voluntary action by the electronics industry, miners and the Congolese government. Thus, some solutions provided in the wake of the perturbation furnished potentially valuable resources which were conductive to entrepreneurial transformation of inputs, such as conflict-free components, into new economic outputs (Hiatt et al., 2009; Sine et al., 2005).

Issue Framing and Resource Transference. While a field-wide perturbation may increase the availability of entrepreneurially-valuable resources, resource holders have to transfer those resources to (eventual) entrepreneurs. Social movement scholars have argued that SMOs' action-oriented frames are important to the resource transfer process (Benford and Snow, 2000). Resource holders are likely to extend material support to an SMO if the SMO's frame is internally consistent, the claim-maker credible, and the frame resonates with resource holders' values and beliefs (Benford and Snow, 2000). Consistent with these social movement 
scholars, we find that the Fairphone campaign mobilised ideas and symbols that conveyed social meaning to audiences. Fairphone's founders employed a comprehensible material artefact - a smartphone - to co-opt the attention of the media, NGOs, the public, mobile network operators, and consumer electronics firms to the problem of conflict minerals and link those audiences tangibly and intuitively to the DRC. Unlike social movement scholarship, however, which portrays SMOs' framing actions as deliberate issue 'packaging' intended to achieve utilitarian ends (Benford and Snow, 2000; Oliver and Johnston, 2000), we find that Fairphone's campaign framing was not intended to achieve any stable, concrete domainspecific goal.

Heterogeneous, distributed actors then channelled entrepreneurially-valuable resources towards the firm founders and/or granted moral legitimacy—essential building blocks for the formation and survival of new ventures - to the eventual entrepreneurs because: (1) diverse solutions were available within an organisational field in the wake of an regulatory perturbation. Some of these solutions provided valuable input (resources) for a new social venture; and (2) Fairphone's issue framing resonated with the values of audiences agents, some of whom were responding to the perturbed industry context.

Despite having no pragmatic legitimacy (Aldrich and Fiol, 1994; Suchman, 1995), Fairphone's founders attracted significant amounts of material resources from actors such as MNOs and customers across Europe. These actors proactively channelled resources to Fairphone, in part, because they judged that Fairphone was morally legitimate, i.e. that Fairphone was doing 'the right thing.' This finding challenges the assumption that new ventures lack legitimacy (Überbacher, 2014). Furthermore, the findings suggest that by commanding a high level of moral legitimacy, venture founders may overcome pragmatic legitimacy concerns among evaluators of the venture's legitimacy in order to attract resources. 


\section{Effectual Entrepreneurial Action}

By acting within expanded means, interacting with an effectual network and leveraging contingencies, some of which were provided occur due to the action of distributed agents, Fairphone's founders translate the translates the endowments of distributed agents (material resources, legitimacy) into a new venture. The observed effectuation process highlights an important aspect of effectuation: the role of material artefacts. Prior empirical studies of effectuation have shown how an effectual network make affordable loss pre-commitments in the form of idiosyncratic knowledge, networks, and resources to the proprietors of some technological artefact (Sarasvathy and Kotha, 2001; Sarasvathy and Dew, 2005; Sarasvathy, 2008, p. 246-254). However unlike in previous studies, we find that the effectual network did not commit resources in order to further instrumental ends, but did so because the social venture employed a material artefact as a symbol of their beliefs and moral values (Haveman and Rao, 1997).

The nature of the artefact - ubiquitous, emotional and tangible — connected to the lives of audiences enabled them to make commitments that they might not have made otherwise. For members of the effectual network, acting on the artefact was a tangible expression of morality (Fuentes, 2014). We believe our findings on distributed agency and role of material artefacts make interesting contributions to effectuation theory and the literature on boundary objects.

\section{Contributions and Future Research Directions}

Effectual Agency as Co-constituted by Distributed Agency. Effectuation theory assumes that agency for a new venture inheres in the entrepreneurial actor (Sarasvathy, 2001; Sarasvathy, 2008, p. 15-16). The theory overlooks how actors located in the effectuator(s)' broader environment are implicated in the emergence of a successful new venture (Arend et al., 2015). We argue that agency does not lie solely with the entrepreneur or even the effectual network. The entrepreneurial intention and capabilities that are presupposed by a purposive enactment 
of the venture in effectuation theory may also originate from multiple actors external to the founding team. We do not imply that the effectual entrepreneur passively complies with the dictates of these distributed actors to channel their varied aspirations into a final artefact. Instead, we suggest that distributed agency co-constitutes or enables effectual entrepreneurial agency in the creation of a new social venture in two ways: (1) by the proactive commitment of entrepreneurially-valuable material resources, legitimacy, capabilities and contingencies to the (eventual) entrepreneurial actor, which is necessary for the new venture to thrive (Zimmerman and Zeitz, 2002); and (2) by provoking a change in the intentions of a reluctant entrepreneurial actor to pursue domain-specific entrepreneurial goals - a necessary condition for the emergence of a new venture (Katz and Gartner, 1988).

Social movements, which are characterised by the contestation of prominent social practices (Weber et al., 2008), may provide a fertile ground for distributed agency because the heterogeneous actors within a social movement are collectively interested in addressing some social problem. Garud and Karnøe (2003, p. 280) suggested that distributed agency in the field of technology entrepreneurship entails 'the presence of multiple actors with different levels of involvement.' It may be that in the context of social enterprise formation higher levels of involvement by distributed agents involve the transference of material resources to the effectual entrepreneur, whereas lower levels of involvement translate to legitimacy evaluations.

The Material Artefact in Effectuation Theory. Material artefacts are central to effectuation theory. For instance, Sarasvathy's (2001) seminal paper was based on experiments in which expert entrepreneurs devised ways to market an imaginary entrepreneurial game (Sarasvathy, 2008, p. 19-40). Similarly, the dynamic model of effectuation was induced from a study of an industry artefact, RFID [Radio Frequency Identification Technology] (Sarasvathy and Dew, 2005; Sarasvathy, 2008, p. 240-254). Yet, the role of the artefact in convening the effectual 
network, which is crucial to the emergence of new firms (Sarasvathy, 2008, p. 105-109), has not been explicated.

Material artefacts may influence the affective ways in which the effectual network is assembled. Social entrepreneurs, like their commercial counterparts, perform meaning work; they produce and mobilise ideas and meaning to make their ventures comprehensible to target audiences. They may do this by 'story-telling' (Lounsbury and Glynn, 2001) or by other symbolic actions calculated to increase legitimacy with key resource holders (Zott and Huy, 2007). Meaning work may involve socio-material considerations since various social groups attribute functional and symbolic attributes to artefacts (Rafaeli and Vilnai-Yavetz, 2004; Shavitt, 1990). Thus, members of an effectual network centred on the creation of a material artefact make inferences about the artefact based on their shared interpretations of the artefact (Bijker, 1987; Pratt and Rafaeli, 1997; Zott and Huy, 2007).

The symbolic dimension may be more salient in the case of social enterprises predicated on addressing a morally-charged social problem. Actors may attempt to infuse moral values into the inchoate social enterprise, the purveyor of the artefact, more than might be the case in commercial enterprises introducing risky technological innovations (Fourcade and Healy, 2007). Thus, members of the effectual network self-select and pre-commit resources to the social enterprise not because they expect immediate calculative benefits from the artefact, but because the artefact embodies and symbolises their beliefs and values.

Boundary Objects in Non-hierarchical Interactions. Boundary objects are artefacts that are agreed and shared between communities of practice. They are 'plastic enough to adapt to local needs and constraints of the several parties employing them, yet robust enough to maintain a common identity across sites.' (Star and Griesemer, 1989, p. 393). In our study, a material artefact, a fair smartphone, served as a boundary object. The artefact was not only tangible and ubiquitous in the developed world, but also connected users through a complex supply chain 
to parts of Asia and Africa. Furthermore, members of various social domains attributed multiple meanings to the artefact. For consumer electronics firms and government actors, the smartphone provided a concrete demonstration of progress on conflict mineral initiatives. For consumers, the smartphone was a way to express their beliefs in fairness and ethical consumption. For hackers, the phone provided an alternative to the closed designs of dominant smartphone producers. In other words, the material artefact occupied different social worlds.

In the organisational literature, boundary objects such as project timelines and engineering drawings have been invoked to explain inter-disciplinary collaboration mostly within the context of a single organisational hierarchy (Nicolini et al., 2012; Yakura, 2002). We argue that the concept of boundary objects might be extended to cover interactions of loosely-coupled actors located in multiple domains that are not bounded within an organisational hierarchy and whose inhabitants have no mutual relations of dependence. Such objects, as Nicolini et al. (2012, p. 614) observed have a 'deep emotional holding power' and are potent enough to mediate interactions and trigger commitment of resources and expression of values by these dispersed actors.

Implications for Practice. Our findings show that to facilitate the distributed accretion of resources and legitimacy, social entrepreneurs could embed themselves in communities of practice (Hargrave and Van de Ven, 2006) that coalesce around addressing a social problem. Even if they are embedded in communities of practice, social entrepreneurs still need to retain their distinctive identities in order to attract resources (Lounsbury and Glynn, 2001; Van de Ven, 1993). Our findings imply that social entrepreneurs could incorporate a comprehensible material artefact into their entrepreneurial narratives and carefully positioning their enterprises' solution as cognate with, but distinct from extant product or service categories in other to attract resources. 
Effectual entrepreneurial action is not always possible, or even desirable; it is applicable in environments characterised by uncertainty (Arend et al., 2015; Sarasvathy, 2001). Our findings also suggests that social entrepreneurs need capabilities to assess which contributions are critical inputs to the effectuation process and to understand how they may be successfully accumulated and exploited. To this end, social entrepreneurs may seek to balance their resource-seeking attempts between proactively pursuing contributions and releasing time to act upon contributions and contingencies offered by actors affiliated with those communities of practice.

Future Research. Our study raises several questions for future inquiry. First, future research could examine how entrepreneurial decision making patterns change in the life of a social enterprise. Read and Sarasvathy (2005) proposed that successful social enterprises are more likely to have begun by effectual entrepreneurial action and grown through causal entrepreneurial action as the organisations endure over time. Scholars could explore this prediction using an in-depth longitudinal multiple case study to examine decision making patterns in social enterprises that originally emerged through effectual action.

Second, while distributed agency enables effectual action in the early phases of the enterprise how does the nature of distributed agency change as the enterprise grows? If as the enterprise matures and decision making processes become more causal, does the heterogeneity and motives of the previously distributed agents change? Do they, for instance, make calculative contributions to the enterprise, instead of proactive, value-driven contributions?

Third, though scholars have begun to appreciate the importance of material artefacts in the field of organisation studies (e.g., Nicolini et al., 2012; Yakura, 2002), little attention has been paid to the role of objects in social entrepreneurship. How might the nature of material artefacts influence effectual commitment in social entrepreneurship? In our study, there was broad agreement on the functional as well as the symbolic dimensions of the artefact. What if 
Fairphone's founders had campaigned using another material artefact, say an electric toaster? If there is low agreement on either functional or symbolic dimensions, would the effectual network commit resources in similar ways? We welcome scholarship investigating the role of material artefacts in social entrepreneurship within loosely-coupled collectives (Haugh, 2007; Montgomery et al., 2012).

\section{LIMITATIONS AND CONCLUSION}

Despite its contributions, our study has at least two limitations. First, we relied principally on interviews to reconstruct Fairphone's story before October 2013. We were careful to eliminate bias by triangulating informant reports and by seeking informants who were critical of Fairphone. Yet, we still feel residual concern that bias was not completely eliminated. Second, Fairphone is but one organisation. It emerged within a perturbed industry context in an economically-advanced part of the world. While our study offers rich insight into social enterprise emergence, we do not know whether our empirical findings are transferrable to other empirical settings.

Social entrepreneurship scholars have often depicted social entrepreneurs as visionary individuals who drive social change by innovatively combining resources (Dacin et al., 2011; Mair and Martí, 2006). We highlight social enterprise emergence as driven by a distributed agents who provide the impetus to eventual effectual entrepreneurs. An effectual network precommits resources to the emerging social enterprise not based on instrumental exchange calculations, but because the artefact served as a boundary object, accessible to multiple social worlds and as embodying moral values of network members.

Due to changing public expenditure priorities, social enterprises are being called upon to address social problems (Haugh, 2007; Santos, 2012). Social enterprises need to be innovative as they reconfigure resources into new organisations, products and services to address these social problems as well as commercially-viable in order to have sustainable impact. These are 
formidable challenges for social entrepreneurs operating in highly-competitive market environments. Yet, in the face of human suffering, social enterprises may find themselves surrounded by a groundswell of supporters who, given the opportunity to express moral values, commit resources to address those challenges. 
[1] Except for Fairphone's founders, Bas van Abel, Peter van der Mark and Miquel Ballester, His Royal Highness (H.R.H), Prince Jaime de Bourbon de Parme and Waag Society, the names of all informants have been changed to protect their identities.

[2] We thank an anonymous reviewer for highlighting this aspect of effectuation theory.

[3] The first author did not receive remuneration from Fairphone during his fieldwork in the organisation. Other than an agreement to respect the confidentiality of Fairphone members, Fairphone's leaders put him under no obligation.

[4] Fairphone is incorporated as a limited liability company. In the Netherlands, there is no legal organisational form to distinguish social enterprises from commercial enterprises. Fairphone's claim to be a social enterprise is based on its operations and governance model. In 2015, the company obtained B-Corp certification as a "for-profit company certified by the nonprofit B-Lab to meet rigorous standards of social and environmental performance, accountability, and transparency.” (https://www.bcorporation.net/community/fairphone)

[5] Defects during prototype testing phase ranged from the functional, such as improperly functioning power buttons, to the aesthetic (e.g., barely-perceptible scratches on the screen). Defects in late December 2013 were all slight aesthetic defects. 


\section{REFERENCES}

Aldrich, H. E., \& Fiol, C. M. (1994). 'Fools rush in? The institutional context of industry creation'. Academy of Management Review, 19, 645-70.

Alvord, S. H., Brown, L. D., \& Letts, C. W. (2004). 'Social entrepreneurship and societal transformation: An exploratory study'. Journal of Applied Behavioral Science, 40, 26082.

Arend, R., Sarooghi, H., \& Burkemper, A. (2015). 'Effectuation as ineffectual? Applying the 3E theory-assessment framework to a proposed new theory of entrepreneurship'. Academy of Management Review, 40, 630-51.

Baker, T., \& Nelson, R. E. (2005). 'Creating something from nothing: Resource construction through entrepreneurial bricolage'. Administrative Science Quarterly, 50, 329-66.

Bartley, T. (2007). 'How foundations shape social movements: The construction of an organizational field and the rise of forest certification'. Social Problems, 54, 229-55.

Benford, R. D., \& Snow, D. A. (2000). 'Framing processes and social movements: An overview and assessment'. Annual Review of Sociology, 26, 611-39.

Bijker, W. E. (1987). 'The social construction of bakelite: Toward a theory of invention'. In Bijker, W. E., Hughes, T. P. and Pinch, T. J. (Eds), The Social Construction of Technological Systems: New Directions in the Sociology and History of Technology. Cambridge, MA: MIT Press, 159-187.

Braun, V., \& Clarke, V. (2006). 'Using thematic analysis in psychology'. Qualitative Research in Psychology, 3, 77-101.

Corner, P. D., \& Ho, M. (2010). 'How Opportunities Develop in Social Entrepreneurship'. Entrepreneurship: Theory \& Practice, 34, 635-59.

Dacin, M. T., Dacin, P. A., \& Tracey, P. (2011). 'Social entrepreneurship: A critique and future directions'. Organization Science, 22, 1203-13. 
Davis, G. F., McAdam, D., Scott, W. R., \& Zald, M. N. (2005). Social Movements and Organization Theory. New York: Cambridge University Press.

Di Domenico, M., Haugh, H., \& Tracey, P. (2010). 'Social bricolage: Theorizing social value creation in social enterprises'. Entrepreneurship: Theory \& Practice, 34, 681-703.

Dutton, J. E., \& Dukerich, J. M. (1991). 'Keeping an eye on the mirror: Image and identity in organizational adaptation'. Academy of Management Journal, 34, 517-54.

Eisenhardt, K. M. (1989). 'Building theories from case study research'. Academy of Management Review, 14, 532-50.

Fourcade, M., \& Healy, K. (2007). 'Moral views of market society'. Annual Review of Sociology, 33, 285-311.

Fuentes, C. (2014). 'Green materialities: Marketing and the socio-material construction of green products'. Business Strategy and the Environment, 23, 105-16.

Gartner, W. B. (1985). 'A conceptual framework for describing the phenomenon of new venture creation'. Academy of Management Review, 10, 696-706.

Garud, R., \& Karnøe, P. (2003). 'Bricolage versus breakthrough: Distributed and embedded agency in technology entrepreneurship'. Research Policy, 32, 277-300.

Gronn, P. (2002). 'Distributed leadership as a unit of analysis'. Leadership Quarterly, 13, 423-51.

Hargrave, T. J., \& Van de Ven, A. H. (2006). 'A collective action model of institutional innovation'. Academy of Management Review, 31, 864-88.

Haugh, H. (2007). 'Community-led social venture creation'. Entrepreneurship: Theory \& Practice, 31, 161-82.

Haveman, H. A., \& Rao, H. (1997). 'Structuring a theory of moral sentiments: Institutional and organizational coevolution in the early thrift industry'. American Journal of Sociology, 102, 1606-51. 
Hiatt, S. R., Sine, W. D., \& Tolbert, P. S. (2009). 'From Pabst to Pepsi: The deinstitutionalization of social practices and the creation of entrepreneurial opportunities'. Administrative Science Quarterly, 54, 635-67.

Katz, J., \& Gartner, W. B. (1988). 'Properties of emerging organizations'. Academy of Management Review, 13, 429-41.

Langley, A., \& Truax, J. (1994). 'A process study of new technology adoption in smaller manufacturing firms'. Journal of Management Studies, 31, 619-52.

Lounsbury, M., \& Glynn, M. A. (2001). 'Cultural entrepreneurship: Stories, legitimacy, and the acquisition of resources'. Strategic Management Journal, 22, 545-64.

Lumpkin, G. T., Moss, T. W., Gras, D. M., Kato, S., \& Amezcua, A. S. (2013).

'Entrepreneurial processes in social contexts: How are they different, if at all?'. Small Business Economics, 40, 761-83.

Mair, J., Battilana, J., \& Cardenas, J. (2012). 'Organizing for society: A typology of social entrepreneuring models'. Journal of Business Ethics, 111, 353-73.

Mair, J., \& Martí, I. (2009). 'Entrepreneurship in and around institutional voids: A case study from Bangladesh'. Journal of Business Venturing, 24, 419-35.

Mair, J., \& Martí, I. (2006). 'Social entrepreneurship research: A source of explanation, prediction, and delight'. Journal of World Business, 41, 36-44.

McMullen, J. S., \& Shepherd, D. A. (2006). 'Entrepreneurial action and the role of uncertainty in the theory of the entrepreneur'. Academy of Management Review, 31, 13252.

Meyer, A. D. (1982). 'Adapting to environmental jolts'. Administrative Science Quarterly, 27, 515-37.

Miles, M. B., \& Huberman, A. M. (1994). Qualitative Data Analysis: An Expanded Sourcebook. London: SAGE Publications. 
Miller, C. C., Cardinal, L. B., \& Glick, W. H. (1997). 'Retrospective reports in organizational research: A re-examination of recent evidence'. Academy of Management Journal, 40, 189-204.

Montgomery, A. W., Dacin, P. A., \& Dacin, M. T. (2012). 'Collective social entrepreneurship: Collaboratively shaping social good'. Journal of Business Ethics, 111, 375-88.

Nicolini, D., Mengis, J., \& Swan, J. (2012). 'Understanding the role of objects in crossdisciplinary collaboration'. Organization Science, 23, 612-29.

OECD. (2013). OECD due Diligence Guidance for Responsible Supply Chains of Minerals from Conflict-Affected and High-Risk Areas. Paris: OECD Publication.

Oliver, P. E., \& Johnston, H. (2000). 'What a good idea: Frames and ideologies in social movements research'. Mobilization: An International Journal, 5, 37-54.

Patton, M. Q. (2001). Qualitative Research and Evaluation Methods. Thousand Oaks, CA: SAGE Publications.

Plowman, D. A., Baker, L. T., Beck, T. E., Kulkarni, M., Solansky, S. T., \& Travis, D. V. (2007). 'Radical change accidentally: The emergence and amplification of small change'. Academy of Management Journal, 50, 515-43.

Pöyhönen, P., \& Simola, E. (2007). Connecting components, dividing communities: Tin production for consumer electronics in the DR Congo and Indonesia. Available at: http://www.somo.nl/publications-en/Publication_2549/ (accessed 5 September 2014).

Pratt, M. G., \& Rafaeli, A. (1997). 'Organizational dress as a symbol of multilayered social identities'. Academy of Management Journal, 40, 862-98.

Rafaeli, A., \& Vilnai-Yavetz, I. (2004). 'Emotion as a connection of physical artifacts and organizations'. Organization Science, 15, 671-86. 
Rao, H., Morrill, C., \& Zald, M. N. (2000). 'Power plays: How social movements and collective action create new organizational forms'. Research in Organizational Behavior, 22, 237-81.

Read, S., \& Sarasvathy, S. D. (2005). 'Knowing what to do and doing what you know: Effectuation as a form of entrepreneurial expertise'. Journal of Private Equity, 9, 45-62.

Robinson, J. (2006). 'Navigating social and institutional barriers to markets: How social entrepreneurs identify and evaluate opportunities'. In Mair, J., Robinson, J. and Hockerts, K. (Eds), Social Entrepreneurship. New York: Macmillan, 95-120.

Santos, F. (2012). 'A positive theory of social entrepreneurship'. Journal of Business Ethics, 111, 335-51.

Sarasvathy, S. D. (2008). Effectuation: Elements of Entrepreneurial Expertise. Cheltenham, UK: Edward Elgar Publishing.

Sarasvathy, S. D. (2001). 'Causation and effectuation: Toward a theoretical shift from economic inevitability to entrepreneurial contingency'. Academy of Management Review, 26, 243-63.

Sarasvathy, S. D., \& Dew, N. (2005). 'New market creation through transformation'. Journal of Evolutionary Economics, 15, 533-65.

Sarasvathy, S. D., \& Kotha, S. (2001). 'Managing knightian uncertainty in the new economy'. In Butler, J. (Ed.), E-Commerce and Entrepreneurship. Greenwich, CT: IAP, 31-62.

Shavitt, S. (1990). 'The role of attitude objects in attitude functions'. Journal of Experimental Social Psychology, 26, 124-48.

Sine, W. D., \& David, R. J. (2003). 'Environmental jolts, institutional change, and the creation of entrepreneurial opportunity in the US electric power industry'. Research Policy, 32, 185-207. 
Sine, W. D., Haveman, H. A., \& Tolbert, P. S. (2005). 'Risky business? Entrepreneurship in the new independent-power sector'. Administrative Science Quarterly, 50, 200-32.

Sine, W. D., \& Lee, B. H. (2009). 'Tilting at windmills? The environmental movement and the emergence of the US wind energy sector'. Administrative Science Quarterly, 54, 123 55.

Squazzoni, F. (2009). 'Social entrepreneurship and economic development in Silicon Valley: A case study on the joint venture: Silicon Valley Network'. Nonprofit and Voluntary Sector Quarterly, 38, 869-83.

Star, S. L., \& Griesemer, J. R. (1989). 'Institutional ecology, translations and boundary objects: Amateurs and professionals in Berkeley's Museum of Vertebrate Zoology, 190739'. Social Studies of Science, 19, 387-420.

Suchman, M. C. (1995). 'Managing legitimacy: Strategic and institutional approaches'. Academy of Management Review, 20, 571-610.

Suddaby, R. (2006). 'From the editors: What grounded theory is not'. Academy of Management Journal, 49, 633-42.

Überbacher, F. (2014). 'Legitimation of new ventures: A review and research programme'. Journal of Management Studies, 51, 667-98.

Van de Ven, A. H. (1993). 'The development of an infrastructure for entrepreneurship'. Journal of Business Venturing, 8, 211-30.

Van Maanen, J., Sørensen, J. B., \& Mitchell, T. R. (2007). 'The interplay between theory and method'. Academy of Management Review, 32, 1145-54.

Weber, K., Heinze, K. L., \& DeSoucey, M. (2008). 'Forage for thought: Mobilizing codes in the movement for grass-fed meat and dairy products'. Administrative Science Quarterly, 53, 529-67. 
Yakura, E. K. (2002). 'Charting time: Timelines as temporal boundary objects'. Academy of Management Journal, 45, 956-70.

Yin, R. K. (2009). Case Study Research: Design and Methods. Thousand Oaks, CA: SAGE Publications.

Zimmerman, M. A., \& Zeitz, G. J. (2002). 'Beyond survival: Achieving new venture growth by building legitimacy'. Academy of Management Review, 27, 414-31.

Zott, C., \& Huy, Q. N. (2007). 'How entrepreneurs use symbolic management to acquire resources'. Administrative Science Quarterly, 52, 70-105. 


\section{TABLES AND FIGURES}

Table I. Interview Data

\begin{tabular}{|c|c|c|c|}
\hline Organisation name & Sector & Informants, hierarchical position & Number of interviews \\
\hline Fairphone & Social enterprise, consumer electronics & Founder, co-founders, staff, ex-associates & 26 \\
\hline Alpha-Mobile & Mobile network operator & Director & 1 \\
\hline Beta-Mobile & Mobile network operator & Product and sustainability managers & 3 \\
\hline Delta-Electronics & Consumer electronics & Director & 1 \\
\hline Epsilon-Electronics & Consumer electronics & Director & 1 \\
\hline Mesa & Civil society & Programme managers, consultants & 5 \\
\hline No-waste & Civil society & Founder/director & 1 \\
\hline Nordic & Civil society & Programme managers & 2 \\
\hline Designco & Product development $\&$ design & Founder/CEO & 2 \\
\hline Gov & Government of the Netherlands & Ambassador & 1 \\
\hline Zeta-capital & Venture capital & Founder/CEO & 1 \\
\hline Eta-investment & Angel investor & Majority investor, Fairphone & 2 \\
\hline Journalist & Media & Newspaper columnist, sustainability blogger & 1 \\
\hline
\end{tabular}


Table II. Evidence for Emergent Themes from Analysis and Illustrative Data

Themes and categories

Illustrative data

\section{Theme 1: Perturbed contextual condition}

Awareness of failure '[Before Dodd-Frank Act] was actually law...they [industry association] understood that there was concern being addressed to them by various NGOs that mineral trade from Congo was facilitating fighting and armament in the Eastern provinces of the DRC...So what was occurring with some of the members of the EICC, particularly the electronic consumer brand companies, [they] were being attacked by various NGOs in terms of the fact that they didn't consider their supply chain sufficiently, that they didn't fully understand or appreciate what might happen with their buying choice.' (Director, Delta-Electronics)

Disruption event Dodd-Frank Act. 'There are a lot of companies that because of the uncertainties [after Dodd-Frank Act] told their smelters, 'Don't source from that region [Central Africa]. We don't have to submit additional regulatory compliance issues such as the conflict minerals report.' You had people—-because of the uncertainty—discontinue their supply. They said, 'I want a fixed price of tantalum that I can deal with, that I know. Or sign a long-term agreement with a mine or smelter that doesn't source from the DRC, just so I know.' (Director, Epsilon-Electronics) Avoiding. Avoid sourcing from DRC altogether (mining companies, smelters) 
Legislating. U.S industry groups legally challenge SEC on Dodd-Frank (2013)

European legislator and NGOs call for European version of Dodd-Frank Act. 'Since the adoption of the Dodd Frank Act in the US I... have emphasized the need for European legislation to stop the trade in conflict minerals. In late 2010 an overwhelming majority of the European Parliament adopted a resolution inviting the European Commission to draft new legislation on this. (Judith Sargentini, Member of European Parliament, in Report on conflict mineral legislation, May 2011).

Engagement. Establishment of conflict-free metal initiatives in DRC (Government of the Netherlands, consumer electronic companies); OECD provides platform for negotiation between civil society, government and industry.

\section{Theme 2: Issue framing}

Ideals of practice

Transparency. 'In order to give insight into the complex and still opaque supply chain, Fairphone has decided to develop her own mobile phone. By building her own phone, Fairphone exposes the relationships in the supply chain and the accompanying global problems.' (Rationale for Fairphone in grant application, January 2011).

Fairness. Mesa fights for equal rights and fair distribution of wealth. In this fight, we run campaigns and involve citizens, consumers, companies and governments. Our vision is for an Africa in which incomes from mineral 
wealth and economic growth is invested in social security for the people.' (Mesa vision statement on grant application, November 2009)

Artefact as storytelling device

Artefact attributes

Tangibility. 'We knew it [campaign] had to be a physical product because otherwise you lose all your research into vagueness.' (Fairphone founder/CEO, Bas van Abel)

Emotionality. '[W]e looked for the electronic device that people cared about the most. Everybody has a smartphone. If I take your smartphone and I walk away with it, you feel really uncomfortable. So different than a television or a tablet.' (Fairphone co-founder, Peter van der Mark)

Ubiquity. 'This [choice of smartphone] was something that happened here [points to chart]. It happened before my time. The phone was definitely intentionally chosen because it is so ubiquitous.' (Fairphone employee)

Material ends Instrumental exchange. Mesa director initially supports Fairphone in order to secure funding from donors. Issue prognosis. [The phone is] like Anne Frank. Of course, terrible....One of the six million [Jews]. It doesn't help telling the story about six million Jews in the second World War or the Germans. It helps when somebody has a symbol which you can use...you need a symbol, which is concrete, which is a specific story' (Angel investor) 
Themes and categories

Establishing category

congruence

'Consumers have a choice of innovative and trendy Blackberrys, iPhones and other Android gadgets. Yet, consumers do not have a choice for a 'fair' variant of these gadgets. Fairphone wants to change the situation'

(Waag Society Magazine, Winter 2010-2011).

Perceptions of actor distinctiveness

David versus Goliath

Urgency versus complacency
'I like[d] the boldness of the [Fairphone] initiative...So it's quite bold to say, "Let's do something about that [conflict minerals]... So that's part of the boldness; it's a very competing [sic], international, full of big, powerful industrial companies; and you just say with four idealistic people..."We don’t know what...but were going to try to see what's the problem and what we can do about it."'(Blogger/Journalist) 'That situation [in the DRC] is unacceptable for consumers who cannot live with the thought that their purchase

\section{Illustrative data}

of a phone supports armed groups in Central Africa...For consumers with a guilty conscience there is hope. The

Fairphone community has since been engaged in a frantic attempt to make a mobile phone which guarantees that your hands stay clean... One thing that the Fairphone promoters hope to achieve: that their plan will shake industry "big boys" out of complacency.' (Article in Vrij Nederland, 23 October 2010) 

set up our own campaign. It's set up as a way to show how bad companies are whereas we wanted to show how good you can do, and what kind of impact you can have as a consumer on changing these things. So we took the positive way.' (Fairphone founder/CEO, Bas van Abel) around the world...And I presented the Fairphone idea. And these guys, they were from India, from Congo, from everywhere. And they were like: "What?”...these guys started laughing...They just completely didn't understand what was going on.' (Mesa programme manager \#2)

Legitimating criteria '[O]ne of the reasons [Mesa stopped supporting Fairphone] was, for example, well, "this is too much of a risk" because we [Mesa] want to be an NGO that does "good" projects. And if we're going to be involved in a project that is already from the start saying, "well, we are never going to be able to [make a $100 \%$ fair product]...This phone still partly stinks... That's reality. So do we want to be involved in that? I don't know.' (Mesa consultant \#1) 


\section{Theme 3: Distributed Agency}

Direct endowments

Legitimacy accretion Media endorsement. 'The billion dollar profits made by Apple and Samsung deserve a counter reaction: the Dutch Fairphone will be fairly produced. And there is a plan. In 11/2 years, the clean smartphone will be available in the shop.' (Newsmagazine NRC.Next, September 2012).

Corporate endorsement. Macrobank, Alpha-Mobile declare support for Fairphone campaign (March 2011).

Public endorsement. Public votes Fairphone winner of prestigious ASN Bank prize for fair trade (November 2011)

Tangible resources

Human capital. Macrobank seconds laid-off project manager to Fairphone free-of-charge (early 2012).

Financial resources. Alpha-Mobile agrees to buy 1,000 non-existent smartphones, contrary to organisation's purchase policies (March 2011). Beta-Mobile gives cash to attend incubator programme (June-July 2012).

Contingent endowments Ex-project manager discovers London incubator. Enlists Fairphone without consultation (May-June 2012); Prince Jaime de Bourbon de Parme invites Van Abel to participate in conflict-free mineral pilot (November 2012). Crowdfunding campaign over-subscribed (Summer 2013). Academics, industry experts volunteer services to firm. 
Table III. Evidence for Effectuation in the Emergence of Fairphone

\begin{tabular}{ll}
\hline Effectuation construct & Illustrative data
\end{tabular}

\begin{tabular}{ll}
\hline Acting within means & Knowledge. Founder/CEO draws on experience as industrial designer to recommend open design of smartphone \\
& as social movement campaign; Mesa activists choose conflict minerals because organisation members had \\
& knowledge of DRC. \\
& Identity. 'It was really practical events that we set up [for the campaign]....because that's what we do at Waag... we \\
& are practical researchers. We are not like academic researchers on fair trade' (Fairphone ex-project manager) \\
\hline Interaction with & Social media updates, face-to-face and online interaction. Meeting with Angel associated with Van Abel's \\
stakeholders & employer. \\
\hline Leveraging & Contingency \#1: Discovery of London incubator programme. Action: Van Abel and Van der Mark cannot attend \\
contingencies & Cull-time. Ask Ballester to represent Fairphone in programme for three months. \\
& Contingency \#2: Discovery of conflict-free mineral projects piloted by Dutch government and consumer \\
& electronics firms. Action: Founder enlists Fairphone as purchaser of conflict-free component. \\
& Contingency \#3: Crowdfunding over-subscribed. Action: Founders produce more phones than initially planned.
\end{tabular}


Affordable loss pre- $\quad$ Volunteers (Expertise). Academics, industry experts volunteer services to firm. Some recruited by Fairphone.

commitments Investors (finance) Venture Capital firm invests $£ 15,000$.

Angel invests $€ 400,000$ in stage-gate manner. 'I asked Bas [van Abel] how much we needed. Then he said, "We need millions.” I said, “No, we don’t need millions. We need $€ 300-400,000$ until the moment that we're really going to produce. So let's make three stages. One is, we need to do this [produce], and then that [second] stage is, “how are we going to finance it?" We made this whole plan. And this was not very much.' (Angel investor) Corporates (industry-specific expertise). Alpha-Mobile, Beta-Mobile, Gamma Mobile test prototype fair smartphone for free (August-December 2013), help Fairphone fix bugs. Beta-Mobile pays for audit of Chinese factory.

Cultural influencers (Legitimacy). 'While I was tearing out my hair over Apple's evasions, Fairphone was launching its first handset at the London Design Festival. This company, formed not just to build a genuine ethical smartphone but also to try to change the way in which supply chains and commercial strategies work, looks like everything that Apple should be but isn't. Though its first phone won't be delivered until December, it has already sold 15,000 sets: to people who want 21st-century technology without 19th-century ethics.' (George Monbiot in UK's Guardian, 24 September 2013) 


\begin{tabular}{ll}
\hline \hline Effectuation construct & Illustrative data \\
\hline Change in goal & Initial goal (2009-end-2011). Raise awareness about conflict minerals and smartphones. \\
& Goal ambiguity (end-2011-mid-2012). 'We were already going about this for a few months [in early 2012] asking, \\
& "What are we going to do with this Fairphone idea? What shall we do next? Should we start our own company?" \\
& It is really scary to go that way, you know. (Fairphone, ex-project manager) \\
& New goal (mid-2012). '[T]he fact that we were accepted in the "bootcamp" in London had a big influence. Until \\
& then, we always said like, "we are making this phone," but there was no asset to do so. There was no money, not \\
& the right relationships...The moment the accelerator [incubator] programme said, and "We want to make this \\
& happen. We believe in your story"...You know, it was like, "yeah, actually we can make this happen." (Fairphone \\
& co-founder, Miquel Ballester) \\
& Networks. At incubator programme, founders meet industry experts, who partner with Fairphone; experts volunteer \\
& technical expertise to Fairphone. \\
& Knowledge. Realisation due to Ballester's research that problems in supply chain include poor factory conditions \\
& and electronic (e)-waste. Increased marketing and industry knowledge from contacts at MNOs.
\end{tabular}


Figure 1. Process Model of Social Enterprise Emergence

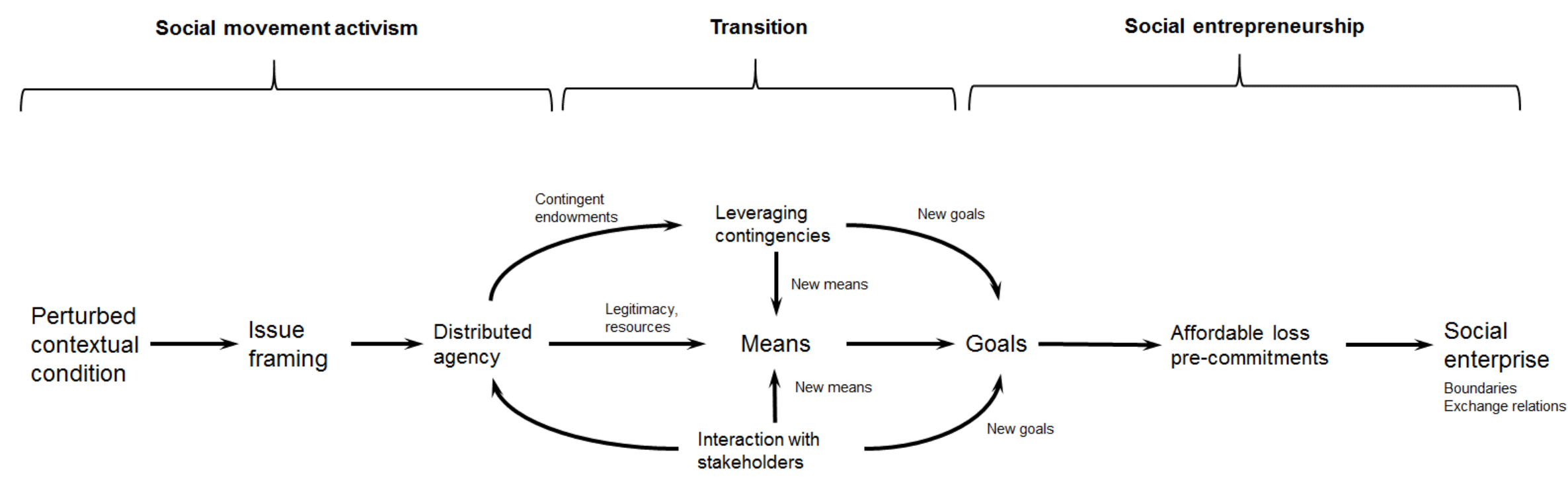

